\title{
Prevention of Industrial Eye Injuries
}

An exhibition dealing with the prevention of industrial eye injuries was opened at the Royal Eye Hospital by the Earl of Athlone, K.G., on June 22. Mr. Vernon Cargill, Chairman of the Hospital, opened the proceedings with an address in which he welcomed the Earl of Athlone and recalled the great interest which Her Majesty Queen Mary has always taken in the work of the Royal Eye Hospital. He pointed out that the numbers of eye injuries attending the hospital showed a steady increase over the past three years and amounted to 7,700 last year.

The hospital has set up an Industrial Eye Injuries Committee on which serve representatives of the National Safety First Association, the Home Office, Members of Parliament and members of the honorary staff of the Hospital. The result has been that an exhibition of protective devices will find a permanent home in the Out-patient Department.

The Earl of Athlone declared the exhibition open and congratulated the hospital on this pioneer movement. He emphasized the importance of prevention in this work.

Mr. Joseph Minton, who has done an immense amount of the spade work which has resulted in this movement, then gave a short address. He alluded to the new Factory Act which will enlarge the scope of compulsory use of goggles and other protective devices, and dealt with the problem of re-education of the one-eyed workman. At the end a film was shown which Messrs. Kodak had kindly prepared.

The Royal Eye Hospital is to be congratulated on this piece of pioneer work in a sight-saving campaign and it is to be hoped that other eye hospitals, especially in manufacturing centres, will soon follow their admirable lead.

\section{ABSTRACTS}

\section{I.-SURGICAL OPERATIONS}

(1) McArevey, J. B. (Dublin).-Corneal transplantation in an aphakic eye. Irish Jl. of Med. Sci., October, 1937.

(1) McArevey here prints a communication made to the Section of Ophthalmology of the British Medical Association, Belfast, July, 1937. He emphasizes the importance of detailed examination of the anterior part of the globe and advises examination by means of 
the slit-lamp, by infra-red photography and by double transillumination. Should an opaque lens complicate the state of affairs, the author states that there are three ways of dealing with it. It may either be removed before the grafting, or at the same time as the grafting is performed or at some date later. Elschnig's opinion is that aphakic eyes are unsuitable for corneal grafting.

McArevey's patient was a man, aged 63 years, poorly nourished and of bad physique, but no general abnormal condition was found; the urine was free from albumen and sugar and the Wassermann reaction was negative. The right eye had been blind for more than 20 years, and the left for four years, both as a result of ulceration. The corneae showed dense central leucomata which reached nearly to the limbus. There was accurate perception of light in each eye.

The patient was admitted to hospital and underwent a good deal of preliminary conjunctival treatment with division of a large anterior synechia.

On March 26, 1936, a corneal grafting was performed on the left eye according to Tudor Thomas's technique. In removing the opaque disc from the patient's eye a band of adherent iris was divided. The lens was seen to be opaque. The eye did well at first but later the graft became opaque and vascularized. Three months later the tension rose and the graft burst open with extrusion of the lens, after which the graft healed in good position and the eye has remained quiet with total corneal opacity.

The patient was anxious to undergo further treatment to improve his vision and so the right lens was extracted and a month later a corneal transplantation was performed. It was decided to place the graft eccentrically to avoid the band of anterior synechia which was present. The eye was soft and the operation difficult. When the disc was removed normal vitreous presented. But, in spite of all this, the result was better than could have been anticipated. The graft healed and remained transparent and after a fortnight a good red reflex was obtained. Vision at four months after the operation was finger counting at 2 metres with $+6.0 \mathrm{D}$. sph.

The author is to be congratulated on his perseverance and success.

R. R. J.

(2) Busacca, A. (S. Paolo).-Introduction of an ivory plate into the anterior chamber in keratoplasty in cases of extensive adherent leucoma. (Einführung einer Elfenbeinschale in der Vorderkammer zur Keratoplastie bei grossem Leucoma adhaerens). Klin. Monatsbl. f. Augenheilk., Vol. XCIX, p. 472, 1937.

(2) Busacca describes a case where in order to facilitate the subsequent plastic operation for leucoma adherens he inserted an 
ivory plate into the anterior chamber through a limbal incision after he had freed all adherent iris from the back of the cornea. The eye showed marked ciliary injection for about a week and then became quiet in about five weeks. The cornea gradually became more transparent and after five months he was able to perform a corneal graft. The author proposes to remove the ivory scale and the cataractous lens at a later date.

\section{R. CAMPBell.}

(3) Moretti, E. (Catania). - A contribution to the surgery of corneal and trachomatous pannus. (Contributo alla chirurgia del panno corneale tracomatoso). Communicated to the Soc. Oftal. Ital., Rome, October, 1937.

(3) Moretti discusses the various medical and surgical methods of treating pannus and their history. He comments on the dangers and complications of some of these procedures.

The author has devised and practised an operation which he calls perirrhaphy or limbus-rhaphy. This operation consists in the passage of a silk suture through the episcleral tissues $3 \mathrm{~mm}$. from the limbus around the entire circumference of the eye. The suture enters the conjunctival and episcleral tissues at " 9 o'clock" in the right eye and " 3 o'clock" in the left eye, traverses $7 \mathrm{~mm}$. of episcleral tissue and is then brought through the conjunctiva and inserted again at or near the point of exit. In this manner it is passed round the circumference of the anterior segment of the eye until it emerges at the original point of entry. Six mm. or so of the suture is left long and is secured to the skin at the outer canthus by adhesive strapping. After 24 hours the eye is dressed, copper sulphate is applied to the affected conjunctiva, dionine drops and atropine ointment are instilled, and thereafter hot bathings and ung. hydrarg. oxidi flavi are added thrice daily to the routine treatment. Periodically the suture is moved through the episcleral tissues in order to increase its irritative action. In the majority of cases the suture is left in situ for 20 to 30 days.

Moretti has treated 42 cases of trachomatous pannus in this manner and claims "excellent" results in the case of active pannus but only moderate results in cases where the pannus is of long standing and relatively avascular.

He believes that the hyperaemia and phagocytosis induced by this treatment are responsible for the improvement.

$$
\text { H. B. Stallard. }
$$


(4) Chandler, P. A. (Boston).-Dacryocystorhinostomy. Trans. Amer. Ophthal. Soc., Vol. XXXIV, p. 241, 1936.

(4) Chandler reviews the history of the dacryocystorhinostomy operation and comments on its many technical features. He reports the results and follow-up of 100 dacryocystorhinostomy operations performed by him or under his supervision.

These he divides into three series (1) Mosher's technique, which includes straightening of the upper part of the septum (but this was not done in Chandler's series), removal of the anterior third of the middle turbinate bone, curettage of the anterior ethmoidal air cells and extirpation of the medial wall of the naso-lacrymal duct. After cutting an oval aperture in the medial wall of the lacrymal sac the anterior lip was sutured to the periosteum of the frontal process of the maxilla. Fifty-three operations were performed on 47 patients and 70 per cent. in this series were successful. (2) The anterior lip of the middle turbinate was removed, the medial half of the lacrymal sac was excised and the nasal mucosa slit vertically opposite the open sac the lips of the incision being sutured to the anterior and posterior edges of the lacrymal sac respectively. No. 4 silk on full curved cutting needles held in Mosquito forceps were used. Eighty per cent. of 25 cases were successful. (3) The anterior tip of the middle turbinate was removed and the tear sac was incised in the form of a $T$, the horizontal incision being $3 \mathrm{~mm}$. from the upper border extending from the anterior to the posterior edge of the lacrymal sac, the vertical cut extending from the centre of the horizontal incision down to the base of the sac. Similar incisions were made in the nasal mucosa and the three flaps thus formed were united by silk sutures, one posteriorly, two superior and one anterior, thus fashioning a tunnel of mucosa running from the sac to the nasal cavity, the top of the sac being held up in its proper position. Twenty-two operations were performed by this technique and all were successful.

H. B. Stallard.

(5) Pagani (Vercelli). - Anaesthesia in ophthalmic surgery. (Procedimanti di anestesia in oculistica). Rass. Ital. d'Ocul., October, 1937.

(5) Pagani gives a short account of the various developments in the production of anaesthesia since Koller introduced cocaine into our practice. There are three forms of anaesthesia which may be produced in various conditions, as required. (1) General anaesthesia, (2) by infiltration, (3) local, superficial by instillation.

General anaesthesia is still necessary in certain cases, especially in children, who have not the self control necessary for operation under superficial anaesthesia. For them the older drugs, chloroform and 
ether, are often unnecessary; avertin is specially suitable for children; if the anaesthesia is not deep enough, it will be possible to produce deep anaesthesia by inhalation without struggling or distress to a small patient. Avertin has its own dangers however in the elderly, and in renal subjects.

Evipan at first seemed to be ideal, and in short operations is still the best. If a longer duration is needed a second dose may be given. It is inadvisable to give a large dose in the attempt to ensure long duration.

For most ophthalmic operations, superficial anaesthesia by instillation of cocaine, is insufficient; it is advisable to produce anaesthesia by infiltration. Injection of novocaine and adrenalin in 0.25 per cent. solution into the tissues around the sensory nerves of the region will give loss of sensation without hindering the co-operation of the patient. Such methods are specially needed when we have to deal with an eye already inflamed, or where the tension prevents the ready absorption of the drug from the surface. Lastly, when the patient is nervous it is advisable to give some nerve sedative before the operation; the combination of morphine and scopolamine is that frequently used with advantage. The author prefers a compound sold under the name of pre-anest-this is bromopialscopolamine in a hypertonic solution of bromide of sodium. Its use, Pagani says, does away with the nausea and vomiting, which may follow other drugs. Children do not take these pre-anaesthetics well and for them it is advisable to employ some other method, probably general anaesthesia.

HAROLD GRIMSDALE.

(6) Imre, J. (Budapest).-Plastic operations of the eyelids. Trans. Ophthal. Soc. U.K., Vol. LVII, Pt. 2, p. 494, 1937.

(6) Imre describes the principles of plastic reconstruction of the lids. He favours the use of adjacent skin wherever possible and covers the defect by a tongue-shaped sliding flap at the extremity of which he excises an elliptical piece of skin to effect sliding and elevation of the flap to the desired extent. The principles of his method are best studied by looking at the illustrations which accompany this paper. He favours the excision of malignant neoplasms from the lids rather than radiotherapy which in a number of cases produces satisfactory superficial healing but allows the growth to extend deeply. Ninety-seven of Professor Imre's cases treated surgically had no recurrence of the neoplasm.

H. B. Stallard. 


\section{II.-MISCELLANEOUS}

(1) Wood, D. J. (the late) (Cape Town).-Night blindness in eye disease - suggestions and speculations. The Doyne Memorial Lecture, Oxford Ophthalmological Congress. Trans. Ophthal. Soc. U.K., Vol. LVII, I't. 2, p. 469, 1937.

(1) Wood suggests that there is a double metabolic system in the retinal pigment epithelium, one which is concerned with the regeneration of the visual.purple for the rods and the corresponding substance (whatever it is) for the cones, in fact the production of photo-chemical substances, and the other serves the general nutrition of the bacillary layer. Experimental work shows that the retina is capable of storing vitamin A, a food factor essential for the maintenance of healthy retinal pigment epithelial cells and their function. There is also experimental evidence to show that vitamin $\mathrm{A}$ is used in the regeneration of visual purple. Dark adaptation is complete only where the retina is in contact with its hexagonal epithelium which is its source of vitamin $\mathrm{A}$, quantities of which are lost in the act of seeing. Vitamin A combines with a protein to form visual purple, while under the influence of light visual purple breaks down again into vitamin A and a colourless substance which is lost, a catalyst being present to promote the former change.

The author discusses the pathology of retinitis pigmentosa. He believes that the prime element in the causation of this disease is to be found in the pigment layer.

He comments on the evidence that the cones contain some photosensitive substance which accumulates in darkness and bleaches very rapidly on exposure to light. He believes that in retinitis pigmentosa there is a further step in enzyme deficiency, an inborn metabolic defect, and that on account of the more complete failure to synthesize visual purple, and later its analogue in the cones, night blindness occurs and the bacillary layers perish. It is probable then that this disease is due to an inborn defect in the intra-cellular enzyme and that its effect is first noticed in the oldest part of the retina, the intermediate zone. Without contact with the retinal pigment epithelium no visual purple is produced from vitamin $A$ in the rods of the retina.

\section{H. B. Staliard.}

(2) Hird, R. Beatson (Birmingham).-The pupil. The Birmingham Medical Review, December, 1937.

(2) In his valedictory address on retirement from the post of President of the Midland Medical Society, Beatson Hird gives an excellent account of the pupil, as regards the anatomical, optical and neurological sides. The embryology of the sphincter and dilatator muscles is fully described and the nervous connexions are illustrated by a couple of diagrams. 
The actions of drugs receive attention and the author gives a clear account of the pupil reactions. He concludes his admirable paper as follows :-

"There is probably no part of the body that, in itself, can be of such diagnostic assistance as the pupil, which indeed we might well name the magic circle. For here we get such valuable help in the diagnosis of various local diseases of the eye, especially glaucoma and iritis. It is in the pupil that we may read of the action of the poisons of opium, belladonna and nicotine, of the toxins of botulism and diphtheria. Here is written large the past infection of syphilis. The pupil reactions will proclaim the genuine epileptic seizure and will decide whether a case of blindness is true or feigned or hysterical. Diseases scattered far and wide in the central nervous system can be run to earth. In the pupil are mirrored the emotions of fear and anger and agony, and it is here that the ever-watchful anaesthetist can read in the widely dilating pupil the danger of impending death."

R. R. J.

(3) Charamis, J. S. (Athens).-Marfan's syndrome. (Le Syndrome de Marfan). Arch. d'Ophtal., New Series No. 12, p. 1067, 1937.

(3) Charamis presents a case which exhibits the characteristic symptoms first described in 1896 to the Société Medicale des Hopitaux de Paris.

The condition has also been described under the term "Arachnodactyly" and as such is referred to in the British Journal of Ophthalmology of April, 1936, p. 238.

The name Marfan's Syndrome was given to the association of ocular symptoms and abnormalities with various alterations in the hands and feet.

The author points out that in many cases the ophthalmologist is the first person to be consulted as the ocular symptoms are usually the first to attract the attention of the patient or his friends.

In the article under review Charamis cites a case that he has had under continuous observation for the past five years and is now ten years old.

He notes that there was absence of ordinary crypts in the iris, together with heterochromia iridis, enlarged eyeballs and corneae. There was also subluxation of the undersized lenses, one up and one down. The suspensory ligament was clearly visible and a remnant of pupillary membrane was present. The lenses were cataractous, the opacity consisting of minute dust-like particles and like the other ocular symptoms these are considered to have an endocrine aetiology. There was also some diplopia referable to the lenticular subluxation, and there was also a high degree of myopia. 
The general symptoms included: emaciation, debility, elongation of the limbs, enlarged tongue, high palate and dental abnormalities, kyphosis, scoliosis, elongation and attenuation of the digits, tallness of stature, dolicocephaly and highly developed interarticular cartilages.

The reproductive system was poorly developed, the cardio-vascular reflex was reversed: low basal rates, low blood-sugar and calcium.

In this case the conditions were congenital: the patient was the only member of the family affected and there was no syphilitic history.

The pituitary and parathyroid glands were considered to be the endocrine glands affected.

The pathology of the condition is still considered to be too obscure to admit of fixing the terminology.

As regards treatment, apart from operative measures for cataract, no satisfactory remedial methods have as yet been determined.

\section{F. R. HILL.}

(4) Shoji, Yoshiharu (Japan).-Clinical appearances and pathology of black or brown cataract. (Clinique et pathogenie de la cataract noire ou brune). Arch. d'Ophtal., New Series No. 12, p. 1057, 1937.

(4) Shoji contributes notes on 18 cases of black cataract together with his views on them and other reported Japanese cases amounting to 36 in all.

He says that under 30 years of age black cataract is the exception, between 51 and 80 it forms 50 per cent. of the cases considered.

In the majority of the cases seen alterations of the fundus were also noted, e.g., choroiditis, retinitis pigmentosa and optic atrophy.

Some granular deposits have been found but were not obvious without the aid of staining.

The causes of the colouration he discusses under the headings of :- (a) blood pigment, (b) sclerosis, (c) melanin. He dismisses from consideration under $(a)$ all those cases which have been complicated with an intra-ocular haemorrhage.

That the appearance is due to the refractive effect on the fibres of the lens caused by sclerosis as was stated by Fuchs he discounts.

The presence of tyrosin as a factor he thinks requires further investigation, and he is inclined to think that the colour may be due to melanin which does not ordinarily form crystals visible to the microscope, though in some unexplained conditions they have been visible as brown-coloured grains of the same hue as the cataract.

He believes the melanin theory to be gaining ground but requires further investigation and the pooling of the results obtained.

F. R. HILL. 
(5) Schieck, F. (Würsburg).-The ophthalmoscopic diagnosis of papilloedema. (Die ophthalmoskopische Diagnose der Stauungspapille). Arch.f. Ophthal., Vol. CXXXVII, p. 203.

(5) For the early diagnosis of papilloedema with the ophthalmoscope by the direct method Schieck relies on the presence of a haze over the central vessels or along the perivascular glia spaces at any point in the physiological cup of the optic disc. This haze, at first faintly but gradually more definitely obscuring these vessels, is due to an exudation under the membrana limitans interna, which is accordingly raised by it; the dilatations of the perivascular spaces, also due to exudate, are frequently observed, although they also occur in the later stages of a neuritis.

The exudate under the limitans interna soon spreads between it and the vessels, and in places also obscures the latter at the margin of the disc.

As the papilloedema subsides the fluid under the limitans also recedes, but remains recognisable for a relatively long time during the process of healing.

In optic neuritis the haze or exudate as above described is absent; the vessels only after a time dip down into the swollen nerve fibre bundles.

In pseudoneuritis too the central vessels lie perfectly clear and unobscured on the nerve fibres; there is no evidence that the limitans interna is raised.

The Gullstrand ophthalmoscope is not, as some writers insist, a suitable instrument for observing these early changes on the papilla.

Thos. SNOWBaLL.

(6) Streiff (Genoa).-Is Fuchs' heterochromia a disease with a special pathogenesis. (L'eterocromia di Fuchs e da considerarsi ancora come forma morbosa con patogenesi propria?). Ann. di Ottal., April, 1937.

(6) Many authors, in treating of Fuchs' heterochromia iridis, have included in their account cases of definite chronic cyclitis; Fuchs was at pains to separate these from the forms which he described; for this reason, some writers have claimed that the disease is commonly an expression of tubercle. Fuchs in his description showed that the K.P. which often accompanies the heterochromia, has special characters, being very small and scattered over all the posterior surface of the cornea. The precipitates are seldom perfectly round but usually have crenate margins. Synechiae are not present. Not infrequently Horner's syndrome may be observed in these cases, indicating disturbance of the sympathetic nerve. In a recent paper Mecca describes the microscopic findings in the heterochromic iris; he shows that there are signs of longstanding chronic inflammation. 
Streiff thinks that this may be due to vascular disturbance following irregular action of the sympathetic.

HAROLD GRIMSDALE.

(7) Stallard, H. B. (London).-Cavernous haemangioma of the orbit successfully removed by Krönlein's operation. Lancet, January $15,1938$.

(7) Stallard reports the case of a man, aged 36 years, whose vision had been failing for nine months. On examination the right eye was displaced upwards and forwards; pupil reactions were normal, ocular movements were normal, papilloedema was apparent in the upper half of the disc, the oedema extending into the adjacent retina, and vision was reduced to finger counting at a metre. The right field was full and an enlargement of the blind spot present. The man was found to be otherwise in good health. The fellow eye was normal in all respects.

It was considered that the condition was neoplastic rather than inflammatory and was situated within the muscle cone, but outside the nerve sheaths.

The orbit was explored by the Krönlein operation and a neoplasm, the size and colour of a ripe damson, was found below and embracing the nasal side of the optic nerve. It was freed by delicate dissection with the tip of the finger, and removed. The patient made a very good recovery, and about five months after operation vision was $6 / 9$, and the pupil reactions and movements of the globe were improving.

The pathological report was a cavernous angioma.

The paper is illustrated by five pictures, showing the incision adopted, the field of operation showing the saw cuts in the outer wall of the orbit, a radiogram taken a week after operation, macroscopic and microscopic appearances of the tumour.

$$
\text { R. R. J. }
$$

(8) Langdon-Brown, Sir Walter (London).- Hormones and vitamins in ophthalmology. Trans. Ophthal. Soc. U.K., Vol. LVII, Pt. 2, p. 454, 1937.

(8) Sir Walter Langdon-Brown discussed the importance of vitamin $\mathrm{A}$ in maintaining the nutrition of epithelium and of affording it an increase of resistance to infective agents. It seems that once the epithelial cell barrier is penetrated by micro-organisms vitamin $A$ has no further influence in combating the infection. Needham found that a pregnant sow fed on a diet in which vitamin A was absent produced young in which the eye cup and lens had failed to form.

Deficiency of vitamin B may cause muco-purulent exudates in the lids, anterior interstitial keratitis, proliferation of lens epithelium (observed in experimental animals but not clinically), retrobulbaı 
neuritis leading to optic atrophy and combined degeneration of the cord.

Lack of vitamin $\mathrm{D}$ during pregnancy had led to zonular cataract, dental hypoplasia and tetany. It is probable that hypocalcaemia is the essential factor in this type of cataract formation.

The author also discussed the part played by the thyrotropic hormone of the pituitary in the production of exophthalmos. Tumours of the pineal gland affect the eyes only by mechanical pressure effects which may lead to bilateral ptosis, modified Argyll Robertson pupils, inability to look up, loss of pupil reflexes and visual field defects.

In describing the ocular complications of diabetes he commented on the fact that temporary ophthalmoplegia, due to neuritis was more frequent before insulin therapy; that diabetics were liable to arteriosclerosis; and that serious retinal complications may result from an ill balanced diet in which the carbohydrates are very low and the fats increased thereby interfering with the effectiveness of the insulin.

\section{H. B. Stallard.}

(9) Maxwell, Euphan (Dublin).-Case of ectopia lentis associated with arachnodactyly. Irish. Jl. of Med. Sci., October, 1937.

(9) A case reported by Miss Maxwell was that of a boy, admitted to an orphanage in 1934, at the age of $10 \frac{1}{2}$ years. No family history was available and the boy was found to have a weak heart and defective vision. His mental condition was subnormal. Two years later he developed a mild toxaemia and the left eye (always the more defective) became blind and painful. On admission to the eye hospital the condition was one of panophthalmitis and Miss Maxwell removed the eye. Subsequent examination revealed a typical example of arachnodactyly. The right eye showed a lens, with peripheral opacities, dislocated up and out, with a wide gap in the suspensory ligament below. The iris was tremulous and the anterior chamber deep. The pupil was $2.5 \mathrm{~mm}$. in diameter and reacted badly to mydriasis. Tension was $20 \mathrm{~mm}$. $\mathrm{Hg}$ and the fundus was normal. Vision with $+9 \cdot 0$ D.sph. $+1^{\circ} 0 \mathrm{D}$. cyl. $45^{\circ}$ was $6 / 12$ part. With +4.0 D. sph. added he read J.2. Without glasses he could read J. 16 held close to his eyes. The field was full.

The appearances seen with the aid of the slit-lamp are described and figured; there are good illustrations of the boy, his hands and feet, with radiographs of each and an electro-cardiograph, and a short bibliography is appended.

The case was communicated to the section of ophthalmology at the annual meeting of the British Medical Association at Belfast, July, 1937.

R. R. J. 